\title{
UNMET NEED OF FAMILY PLANNING AMONG RURAL WOMEN IN BANGLADESH
}

\author{
FERDOUSI SK ${ }^{1}, \mathrm{JABBAR}^{\mathrm{M}}{ }^{2}, \mathrm{HOQUE} \mathrm{SR}{ }^{3}, \mathrm{KARIM} \mathrm{SR}^{4}, \mathrm{MAHMOOD} \mathrm{AR}{ }^{5}, \mathrm{ARA} \mathrm{R}^{1}, \mathrm{KHAN}^{1}$
}

\begin{abstract}
:
Objective: This study aims to find out the unmet need of family planning among the rural women. To explore the obstacles to use family planning methods and to estimate the prevalence of contraceptive use.
\end{abstract}

Study design: Cross-sectional type of descriptive study.

Settings: The study was conducted at Sreepur upazila under Gazipur district.

Subjects: All the married women of reproductive age, residing in a selected village of Sreepur upazila, were selected as the study subject.

Results: The study revealed that unmet need was (22.4\%). Most of the respondents (72.1\%) were using contraceptive methods. Among those who used contraceptives, OCP was the most commonly used method (61.7\%). About 28\% were not using any method. The main reason was fear of side effects (46.1\%).

Conclusion: The study concluded that a nationwide contraceptive prevalence study may be carried out to explore the problem in detail.

Key words: Unmet need, family planning, contraceptive prevalence rate.

J Dhaka MedColl. 2010; 19(1) : 11-15.

\section{Introduction:}

Many of the women of reproductive age and their partners are sexually active and prefer to avoid becoming pregnant, but they are not using any contraceptive method. These women are considered to have unmet need of family planning ${ }^{1}$. Bangladesh is well into the third phase of demographic transition, having shifted from a high mortality-high fertility regime to a low mortality-low fertility one. The uniqueness of demographic transition in Bangladesh is evident from the fact that while worldwide low income country's population grew at an average annual rate of $2.1 \%$ between 1990 and 1997 , the population of Bangladesh grew only at the rate of $1.6 \%{ }^{2}$. Survey research in developing countries estimates that more than 150 million married women of reproductive age have an unmet need for contraception. India has about 31 million women and the majority of African and Middle Eastern countries and in a large number of countries in Asia, Latin America and the Caribbean at least $20 \%$ of married women of reproductive age have an unmet need of contraception. In Bangladesh also the unmet need is as higher as $24 \% .^{3}$ Unmet need does not necessarily mean that family planning services are not available, it may also mean that women lack of information or that the quality of services on offer does not inspire the necessary confidence or that women themselves have little say in the matter ${ }^{4}$. If family planning programmes served most women with unmet need, the demographic impact would be substantial contraceptive prevalence would rise, reducing fertility and slowing population growth. ${ }^{5}$ In 2006, unmet need for family planning was added to the $5^{\text {th }}$ millennium development goal (MDG) as an indicator for tracing process on improving maternal health ${ }^{6}$. Family planning can reduce maternal mortality by reducing the number of pregnancies, number of abortions and the proportion of births at high risks. It can help to

1. Assistant Professor, Department of Community Medicine, Dhaka Medical College, Dhaka.

2. Professor \& Head, Department of Community Medicine, Dhaka Medical College, Dhaka.

3. Medical Officer, Department of Community Medicine, Dhaka Medical College, Dhaka.

4. Lecturer, Department of Community Medicine, Shaheed Suhrawardy Medical College, Dhaka.

5. Lecturer, Department of Community Medicine, Dhaka Medical College, Dhaka.

Correspondence : Dr. Syeda Khaleda Ferdousi 
reduce infant mortality, slow the spread of HIV/ AIDS, promote gender equality, reduce poverty, accelerate socio-economic development, women empowerment and promote the environment ${ }^{7}$. Unmet need is a valuable indicator for national family planning programmes because it shows how well they are achieving a key mission: meeting the population's felt need for family planning. ${ }^{8}$ Researchers estimate that the lives of 150,000 women could be saved each year worldwide with access to sufficient family planning. An estimated 150 million women worldwide want to delay or avoid pregnancy but are not using family planning methods ${ }^{9}$. Most of the married women want to use the contraceptive methods but are unable to use because of lack of knowledge, economical problem, fear of side effects, religious cause, insufficiency of family planning worker, uncooperative husband and limited supply and high cost ${ }^{10}$. At present various active programmes on family planning are running over the few decades but considerate number of people yet not motivated to adopt the family planning in their practical life. The study was conducted to explore the determinants and proportion of unmet need among married women of a selected rural area.

\section{Methods:}

This is a cross-sectional type of descriptive study. The study was conducted at a selected village of Sreepur upazila under Gazipur district. The duration of the study was from June 2009 to December of 2009. All the married women of reproductive age, residing in a selected village of Sreepur upazila, were selected as the study subject. Sample size was 272. Sample was taken purposively. Data were collected by face to face interview of the respondents by using interviewer administered questionnaire. It was duly pre-tested among married women of reproductive age. Considering the objectives, questionnaire was formed consisting both open and close ended questions. The questionnaire contained 22 questions which included the reproductive health condition of the respondents regarding contraceptive practice as well as problems related to unmet need of family planning. The collected data were analyzed by using computer.

\section{Results:}

A total of 272 married women of reproductive age were included in this study. About half of the respondents $(51.8 \%)$ were in the age group of 20-30 years with mean 28.6 years ( $\mathrm{SD} \pm 7.02$ years). About a quarter (26.5\%) of the respondent had completed primary education while $9.9 \%$ were illiterate. Regarding their husbands' educational status, about one fourth of them $(27.6 \%)$ had attended SSC examination and $9.2 \%$ were illiterate. Most of the respondents (94\%) were housewives and lived in nuclear families $(75.7 \%)$. Their mean monthly income was Tk.11, 194.85 (SD \pm 8867.03). Two third of the respondents' income was below Tk.10,000/- Majority of the respondents (87.5\%) experienced pregnancy at least once during the study period and mean number of living child was 2.21 (Table-I). Most of them (96.7\%) had knowledge about contraceptive methods. Nearly three quarter $(72.1 \%)$ of the respondents was using contraceptives and rest was not using any method. Among the non user, ( 5.04\%) of respondent were eager to conceive, $(0.36 \%)$ was sterile and remaining $22.4 \%$ of the respondents, though need family planning methods but due to various reasons, were not getting the facilities, are considered as having unmet need ( Fig.1). Most commonly used contraceptive methods were oral contraceptive pills $61.7 \%$ and condom $21.4 \%$ (Fig.2). Nearly half of the respondents $(46.1 \%)$ were not using contraceptives in fear of side effect. Among other reasons were religious bar, husbands' non cooperation, ignorance about method, not informed by F.P. worker and economical constraints etc, Here multiple response was found. Table-2 showed that use of contraceptive was higher among respondents who experienced pregnancy once or more $(p=0.06)$. It was also found that parity declines with increase level of education though the result was not significant. 
Table-I

Obstetrical characteristic of the respondents

\begin{tabular}{lccc}
\hline Characteristic & No. of living child & Frequency & Percent \\
\hline No. of living child & $1-2$ & 177 & 75.6 \\
& $3-5$ & 57 & 24.4 \\
& Total & 234 & 100.0 \\
Having experience of pregnancy & Yes & 238 & 87.5 \\
& No & 34 & 12.5 \\
\hline & Total & 272 & 100.0 \\
\hline
\end{tabular}

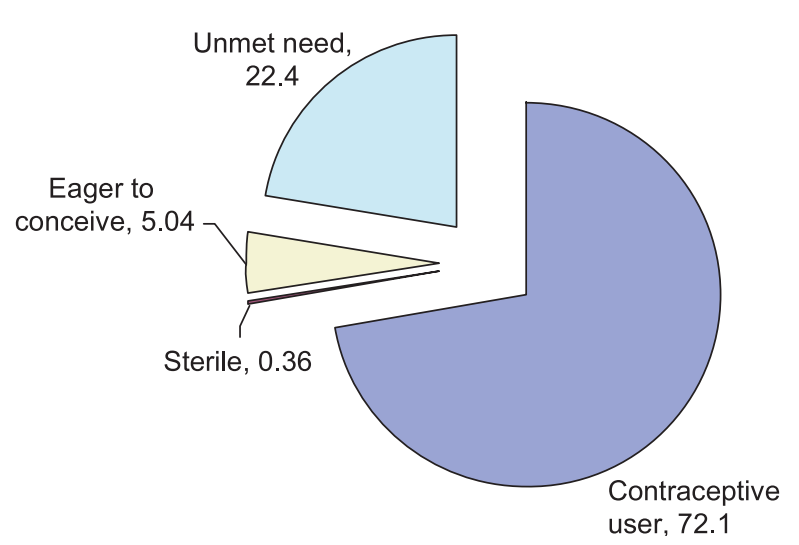

Fig.-1: Proportion of unmet need $(n=272)$

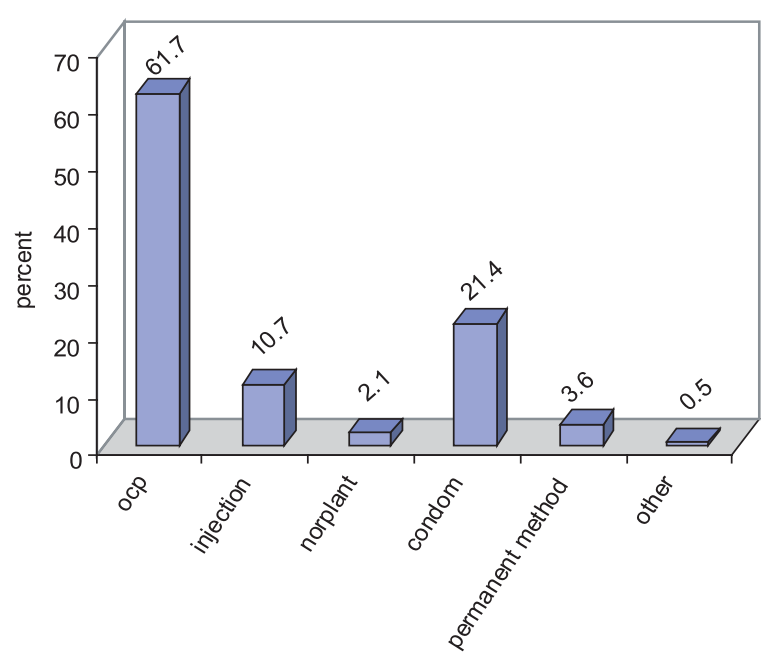

Fig.-2: Contraceptive methods used by the respondent $(n=196)$

Table-II

Relationship between experience of pregnancy and current use of contraceptives

\begin{tabular}{lcccc}
\hline Ever conceived & \multicolumn{2}{c}{ Current user of contraceptive } & Total & Test statistic \\
\cline { 2 - 3 } & Yes & No & & \\
\hline Yes & $176(89.8 \%)$ & $62(81.6 \%)$ & $238(87.5 \%)$ & $\chi^{2}=3.38 \mathrm{P}=0.06 \mathrm{df}=1$ \\
No & $20(10.2 \%)$ & $14(18.4 \%)$ & $34(12.5 \%)$ & \\
\hline Total & $196(72.1 \%)$ & $76(27.9 \%)$ & $272(100.0 \%)$ & \\
\hline
\end{tabular}

\section{Discussion:}

This descriptive cross sectional study was done to explore the proportion of unmet need of family planning among the married woman of reproductive age living in a rural area of Bangladesh. The study also explores the contraceptive prevalence rate, reason for not using contraceptives, the choice of contraceptive by the respondents. Among the respondents $87.5 \%$ have conceived at least once in their life, the rest of the married women $(12.5 \%)$ had never conceived. Study carried out in 2007 in urban slums of Dhaka city, revealed that about one-tenth $(8.3 \%)$ had never experienced pregnancy. Rest of the respondents $(91.7 \%)$ had experienced one or more pregnancies ${ }^{11}$. According to Bangladesh demographic and health survey 2007 (BDHS) it was found that among currently married woman of age group 15-49 years, 9.9\% had 
never gave birth to any child ${ }^{12}$. So, the present study is consistent with the other two studies. ${ }^{11}$, 12 Almost all (96.7\%) the respondents of this study had some knowledge about modern contraceptive methods. Khuda and Howladar (1998) found that knowledge of contraceptive is almost universal among both adolescents and adults in Bangladesh ${ }^{13}$. In BDHS 2007, it was revealed that almost all $(99.8 \%)$ woman of reproductive age of Bangladesh knew about family planning methods ${ }^{12}$. So, it is obvious from various studies that, nearly all married woman of our country had knowledge about contraceptive methods. 2,3,12,14 Contraceptive use rate was $(72.1 \%)$ in present study. According to BDHS 2007, use of contraceptive was overall $(55.8 \%)$ in Bangladesh ${ }^{12}$. Study carried out by Hanif found that only $21.07 \%$ of the total eligible couples were practicing family planning method ${ }^{14}$. As these two data were collected from remote places, so the contraceptive use rate might be low. In a study at Dhamrai thana the contraceptive acceptance rate was (69\%) which is nearer to this study finding. ${ }^{15}$ As the two places are nearer to UH\&FWC and got all facilities and proper services provided by the family planning workers. In this study, most widely used method was oral contraceptive pills $(61.7 \%)$; similar finding was observed in another study ${ }^{14}$ this may be due to easy availability and popularity of these methods. In these studies, permanent method was not so widely used method. Out of 76 respondents who were not using any method of contraception, the principal barrier to use contraceptive was fear of side effect in $(46.1 \%)$ cases. Huq found (18.5\%) in his study. ${ }^{16}$ Study carried out in Nepal, 5 couples out of 8 were contraceptive users. Of these 5 , four quit because of side effects and failed to find an acceptable alternative method. ${ }^{17}$ So side effect is a major barrier to contraceptive use. A number of both perceived and real risks associated with some forms of contraceptives prevent them to use it. Of the respondents $(13.2 \%)$ opined for husbands' non-cooperation in using contraceptives. It has been found that involving husband into FP affairs has the highest significant effect on current use of contraceptive among adolescent. ${ }^{18}$ Study in urban slum revealed (11\%) women mentioned non-cooperation of family members as barrier to contraception ${ }^{11}$. So, this finding is consistent with the present study. In this present study $(11.84 \%)$ women were not using contraceptive due to religious prohibition. Similar findings were observed by Mitra ${ }^{12}(11 \%)$. In this study unmet need of family planning was $22.4 \%$. Jahanara and her associates found 26\% unmet need in their study. ${ }^{19}$ Education increases receptivity to new technology including awareness and use of contraceptives. In a study it was found that educated women had desire for fewer children than their less educated counterparts because of incompatibility between formal sector employment and child care $^{20}$. In present study it was also found parity decline with increased level of education. This study also revealed no association between having experience of pregnancy and contraceptive use. Contraceptive use rate was higher among those who had previous experience of pregnancy. These findings are similar with another study, where contraceptive use rate increases sharply after first child birth. ${ }^{21}$ In view of findings and observations it is revealed, although achievement of family planning programme in Bangladesh is quite satisfactory unmet need is still high. Various obstacles were observed which prevent women from using family planning methods. Raising awareness and continue family planning effort can address unrealistic perception of risk and promote longterm cultural change in favor of family planning among rural women.

\section{Conclusion:}

Majority of the respondents were using contraceptive methods, but a significant number of women were in the group of unmet need. To address this current situation is of great importance which will minimize the unmeet need of family planning to an acceptable level.

\section{References:}

1. Park K. Park's Textbook of preventive and social medicine. 19th ed. Jabalpur: 2007. p.406.

2. Mahmud S, Mahmud W. Rethinking population policy in Bangladesh. CPD- UNFPA Paper Series 24. 
3. The Unmet Need for Contraception in Developing Countries. www.rand.org/pubs/research_breifs / RB5024/index1.html 15th June, 2009.

4. The Unmet Need for Family Planning. www.unicef.org/pon95/fami0007.html 10th June, 2009.

5. Side bars for meeting unmet need: new strategies, Population Reports. http://www.infoforhealth. org/Pr/J43bones. 20th July, 2009.

6. Bernstein S, Eduard L. Targeting access to reproductive health: giving contraception more prominence and using indicator to monitor progress. Reproductive Health Matters. 2007; 15 (29):186-91.

7. Reynolds HW, Janowitz B, Homan R, Johnson L. The value of contraception to prevent perinatal HIV transmission. Sexually Transmitted Diseases. 2006; 33(6): 350-6.

8. Family planning the unfinished agenda. Lancet. 2006; 368:1810-27.

9. Contraceptives Save Lives Meeting the Needs for Family Planning www.unfpa.org/safemotherhood 10th July 2009.

10. Fundamental elements of quality of care: a simple frame work. Stud Fam Plann. 1990; 21(2): 61-91.

11. Amin. Unmet Contraceptive Need Among the Eligible Couples in Urban Slum [MPH thesis]. Dhaka: NIPSOM, University of Dhaka. 2007.

12. Bangladesh Demographic and Health Survey, 2007 (NIPORT, Mitra \& Associates, 2009).

13. Khuda B, Howladar SR. Unmet contraceptive needs and reasons for non-use.1998;
14. Hanif SMA, Bhuiya. Family planning services in a low-performing rural area of Bangladesh: insight from field observation. J Health Pop Nutr. 2001; 19: 209-14.

15. Sarkar. A study on reasons for not accepting family planning method among the eligible couples at selected village. [MPH thesis]. Dhaka: NIPSOM, University of Dhaka; 2007.

16. Huq MN. Interaction between clients and grassroot Family Planning Workers implication For Programme Performance. NIPORT, Bangladesh. 1992; 28-32.

17. Schuler SR. Family Planning in Nepal from users and non-users perspective. Study in Family Planning. 1986; 17(2): 72 .

18. Islam M.M, Mahmud M. Contraceptive among adolescents in Bangladesh. Asia Pacific Pop. J. 1995; 10(1): 21-38.

19. Katun J, Roy Nikhil C, Azim T. Unmet reproductive and child-health needs and use of essential services package in urban NGO clinics of Bangladesh. ICDDR,B Working Paper No.156: 14.

20. Cleland J, Philips J, Amin S, Kamal GM. The determinants of reproductive change in Bangladesh: regional and sectoral studies. World Bank. Washington D.C., USA. 1994.

21. Awal AMM, Islam K, Ara I, Ahmed T. Health, nutrition and population sector. Published by Human Resources Management, Planning and Development Unit, Ministry of Health and Family Welfare, Government of the People's Republic of Bangladesh. 2005; 402. 